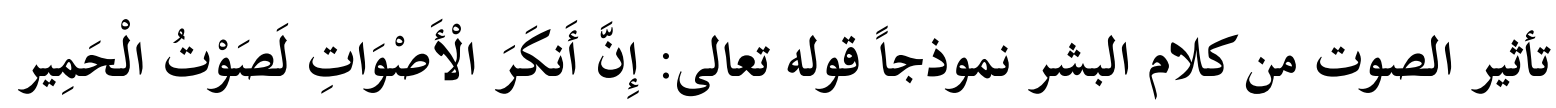

\title{
Influence of Sound from the Words of Human Being with Special Reference to al-Quran (31:19)
}

\author{
MD. NAZMUL HASAN* \& MD. MOZAMMEL HOQUE ${ }^{1}$
}

\begin{abstract}
This article aims to expose the role of sound from people's speech and its effects when they address each other, from the light of the Holy Qur'an and Sunnah. Sound has great importance to convey the message of personal objectives among the people. We speak everyday with our parents, relatives, neighbours and others within our own community and beyond. Consequently, proper addressing with soft sound has paramount benefits. Nowadays many people do not care about this sensitive part, due to the sound intonation sometimes leads to awaken feelings, either positive or negative corner. The Qur'an and the Sunnah give special value in this aspect in the time of conversation with people regardless their religions and tribes even with unbelievers. Allah mentions in the holy Quran when he addressed to Moses and Aaron (peace be upon them): "But speak to him mildly; perchance he may take warning or fear (Allah)" (20:44). This verse indicates to the wonderful style of dialogue with people even if he denies God and does not believe in the Creator of this prolonged universe. Moreover in this paper we will discuss about the impact of sound when they speak with other as well as importance of way for conversation. Apart from that the solution for the negative effects of coarse sounds, in this research we will follow analytical and inductive approach.
\end{abstract}

Keywords: al-Quran, verbal communication, sound, speech

$$
\begin{aligned}
& \text { إنَّ الصوت له دور كبير في حياة الإنسان للتعبير عند الأخرين؛ لأنّ لا نستطيع أن نظهر ما في داخلنا إلا } \\
& \text { بالصوت والكلام مع الغير، ويحتاج عند المحاورة والمحادثة أن يعبر الكلام بالصوت المتواضع دون رفعها أوْ أن } \\
& \text { ينظر إلى الموقف والحال ثم الإلقاء على حسب الطلب ولكن الغالب نحن لا نحتاج إلى رفع الصوت بل } \\
& \text { نستطيع أن نصل مقاصدنا دون رفع الصوت عند الأخرين، واهتم القرآن الكريم والسنة المطهرة هذا } \\
& \text { الجانب، وفى عن رفع الصوت عند الكالام والحوار؛ لأن الصوت الرفيع خلاف المروءة والآداب، وهو ليس } \\
& \text { عادة العالم والمثقف بل هو عادة الجاهلين والمغفلين، والصوت الرفيع له ضرر نفسيا وصحيا، ورافع الصوت }
\end{aligned}
$$

\footnotetext{
${ }^{1}$ Md. Nazmul Hasan*(Corresponding author), Masters student at Dept. of Quran and Sunnah, Faculty of Islamic Revealed Knowledge and Human Sciences, International Islamic University Malaysia, 53100 KUALA LUMPUR, Malaysia, email: nazmul20082001@gmail.com; Md. Mozammel Hoque, Masters student at Dept. of Quran and Sunnah, Faculty of Islamic Studies, Universiti Kebangsaan Malaysia, 43600 BANGI, Selangor, Malaysia, email: mozammel20072013@gmail.com.
} 
لا يضر نفسه فقط بل يضر من حوله وينشئ هذا السوء الظن والفهم بين المخاطِب والمخاطَب ولا

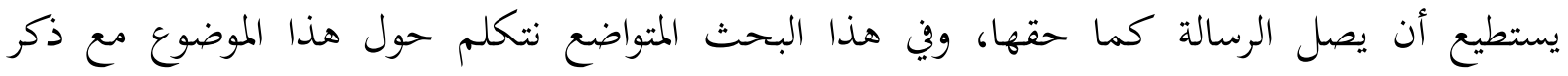

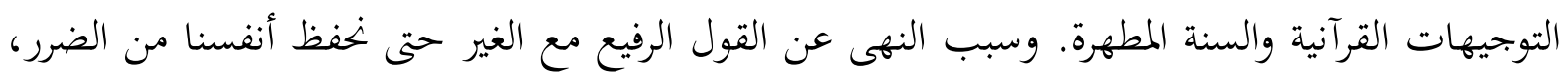

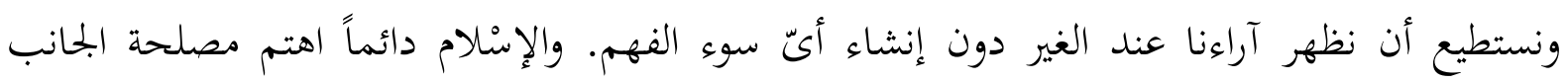

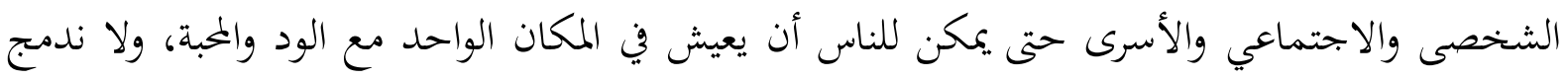

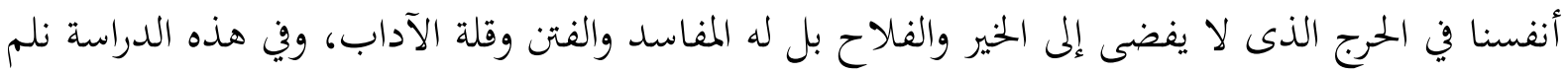

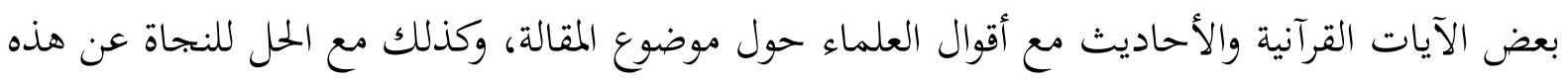
المشكلة الصوتية عند التعبير مع الغير.

\section{مفهوم الصوت عند أهل اللغة}

إذا نتصفح كتب اللغة بحد أن العلماء تكلموا حول هذا اللفظ من جوانب شتى رغم أن أصل المعنى متقارب الأطراف، نذكر هنا بعض أقوال أهل اللغة الذين كان لهم بحثث طويل في هذا الميدان، وفي سبيل

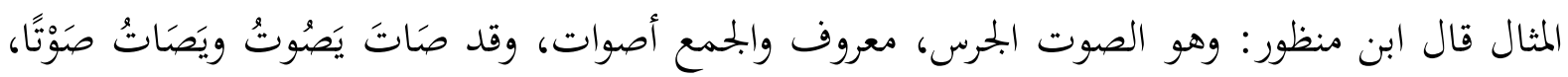

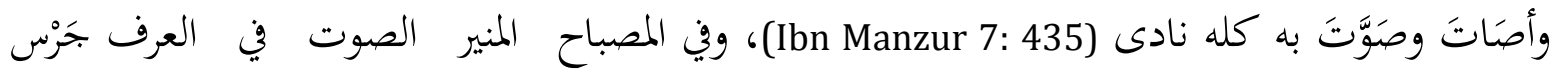

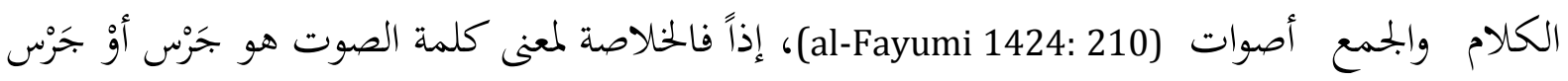
الكلام الذى يحدث عند المحاورة والمكالمة بين الناس.

\section{الصوت من منظور القرآن الكريم}

ذكر في القرآن الكريع دور الصوت ومدى اهتمامه عند الحوار مع الآخرين؛ لأن الصوت له تأثير بالغ بين

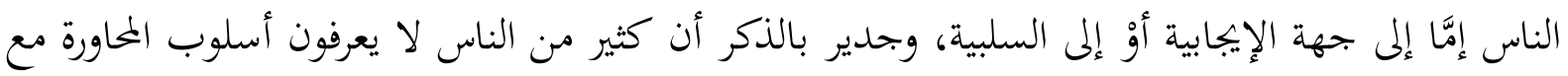

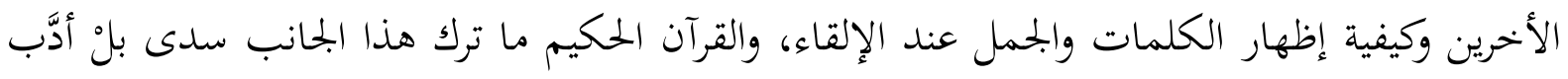

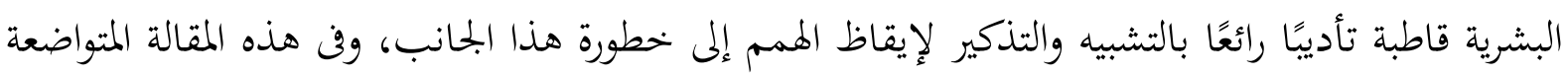

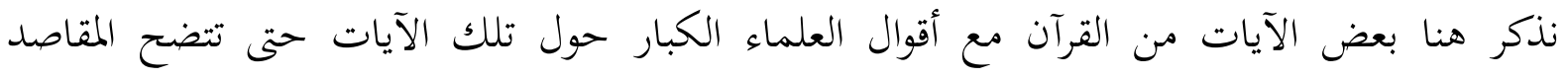

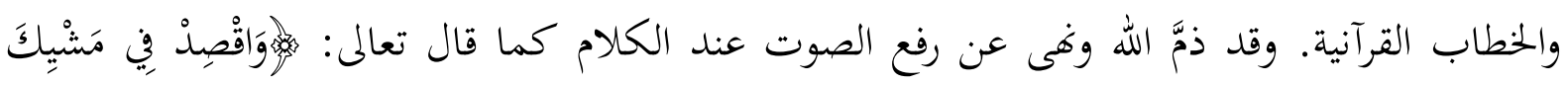

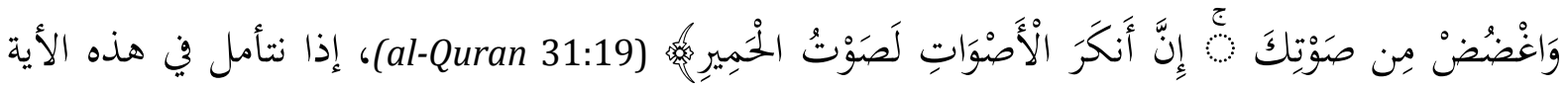


الكريمة بخد أنَّ الله سبحانه وتعالى أمر لشيئين في سياق واحد، ثم بالغ في النهى عند ذكر الشئ الثانى وهو

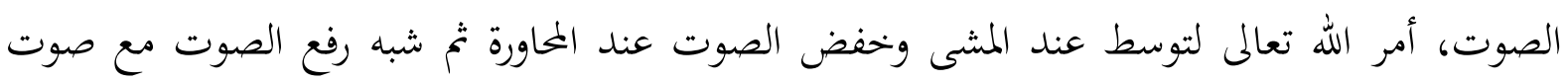

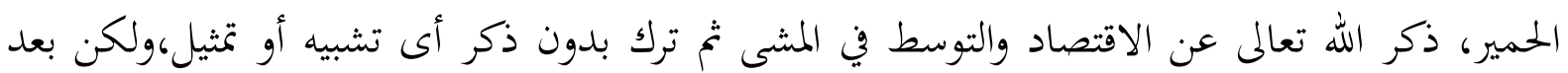

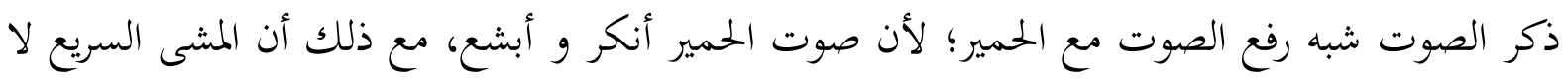

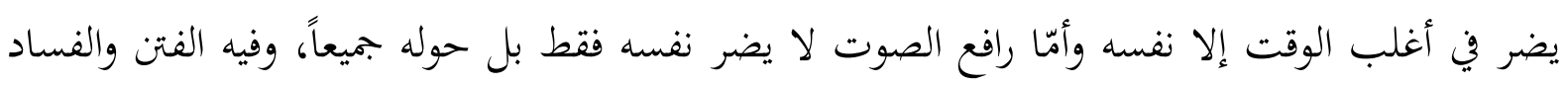

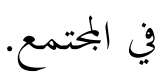

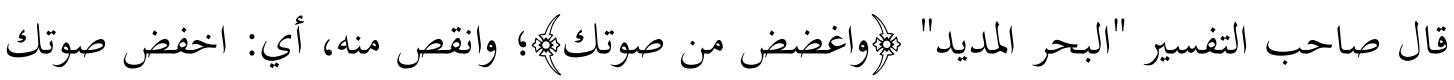

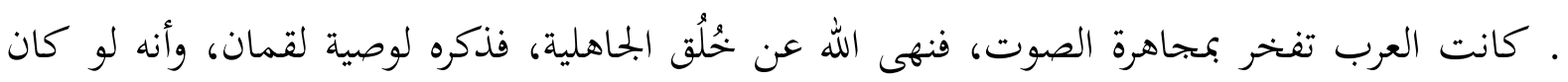

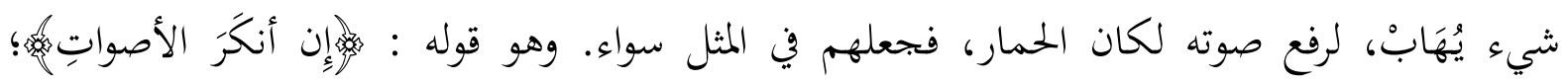

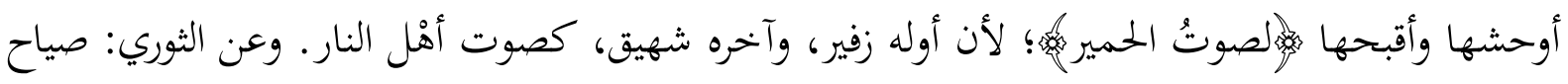

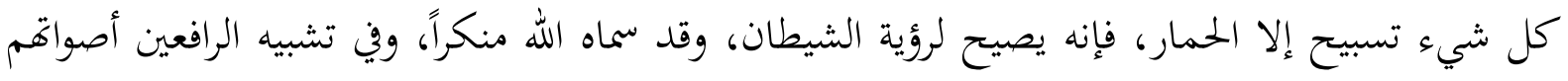

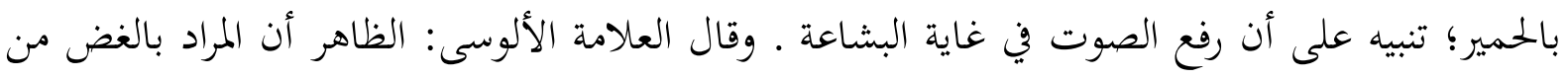

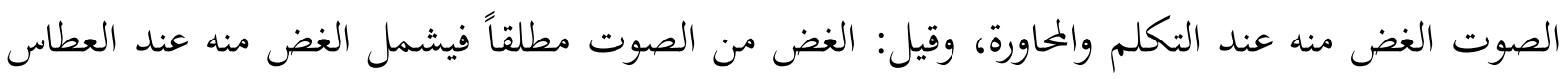

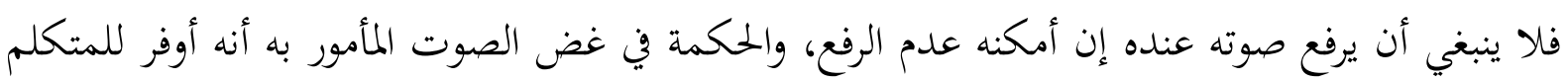

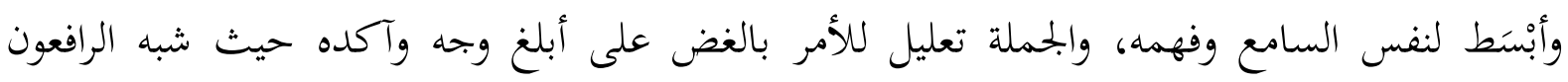

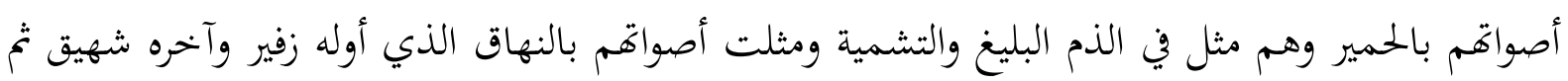

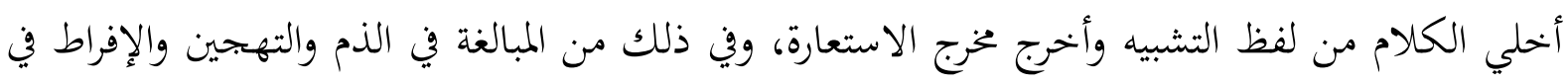
التثبيط عن رفع الصوت والترغيبين عنه ما فيه (al-Alusi 1419 chpt. 16, 5:34) . وذكر العلامة الإمام القرطبي في تفسيره بعض أؤجه حول الأية المذكورة التى تظهر رسالة الأية عند فئد

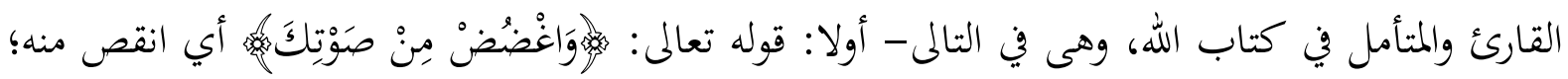

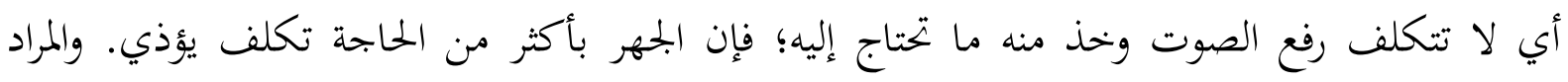

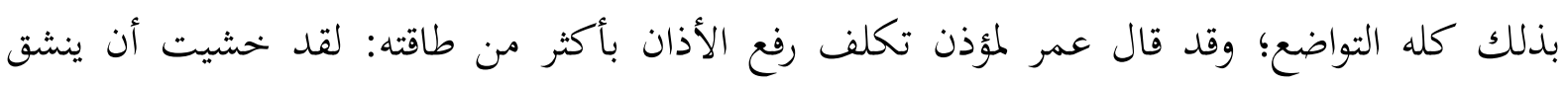

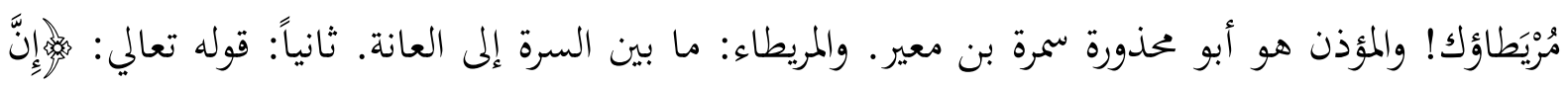

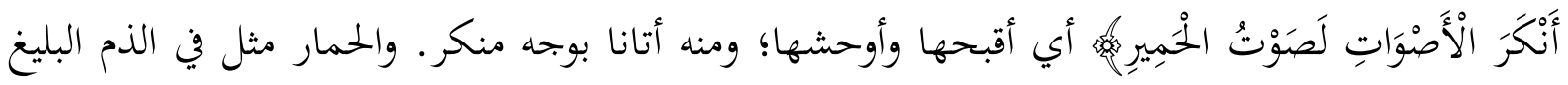

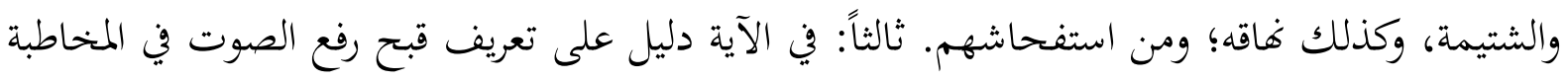

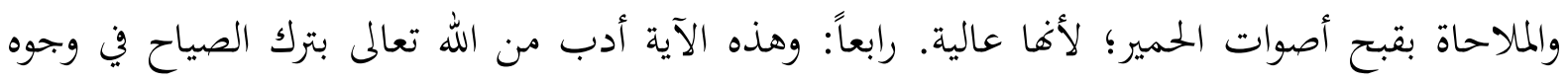


الناس تماونا بهم، أو بترك الصياح جملة؛ وكانت العرب تفخر بجهارة الصوت الجهير وغير ذلك، فمن كان

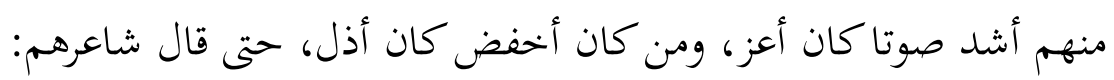

جهير الكلام جهير العطاس ... جهير الرواء جهير النتم

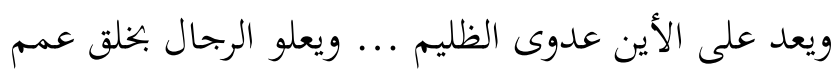

فنهى الله سبحانه وتعالى عن هذه الخلق الجحاهلية بقوله:

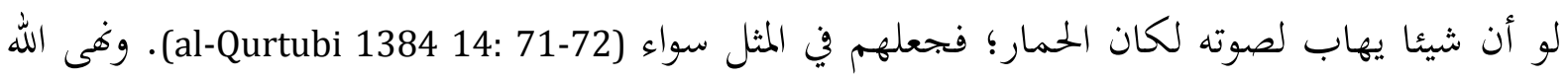
تعالى في أية أخرى عن رفع الصوت أمام حضرة رسول الله ولو هذه الأية خصت مع سئه سيدنا رسول الله

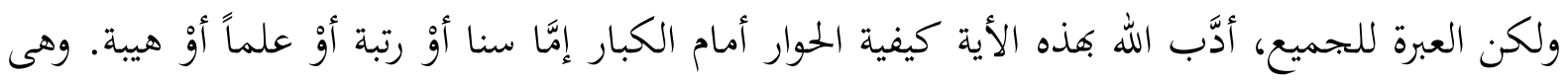

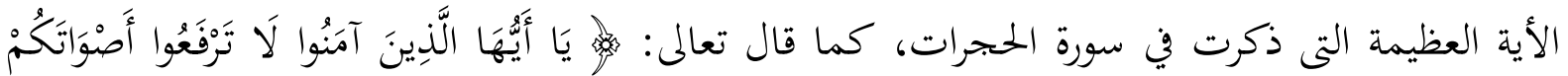

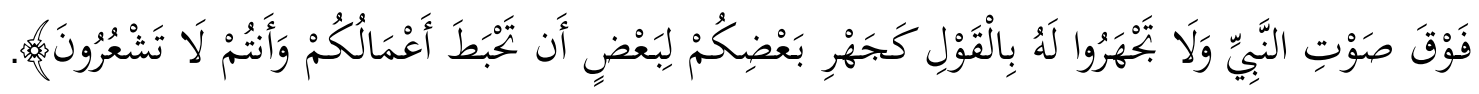
.(al-Quran 49:2)

تكلم العلماء حول هذه الآية المباركة عدة أقوالٍ، نذكر هنا باختصار بعض الآراء حول الأية. قال

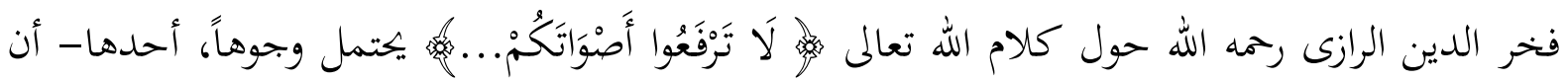

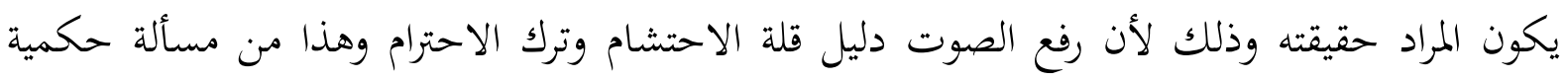

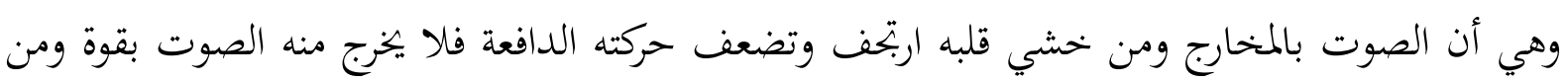
لم يخف ثبت قلبه وقوي فرفع الهواء دليل عدم الخشية. ثانيها- أن يكون المراد المنع من كثرة الكالام؛ لأن من يكثر الكاء دئلام يكون متكلماً عن سكوت

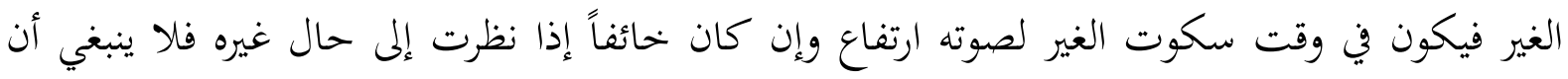

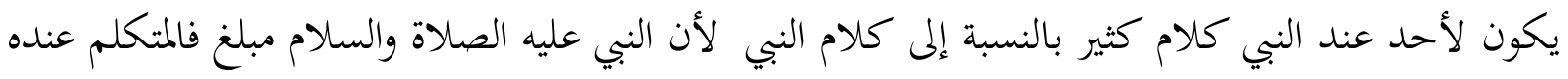

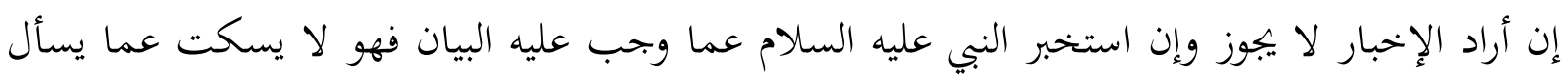

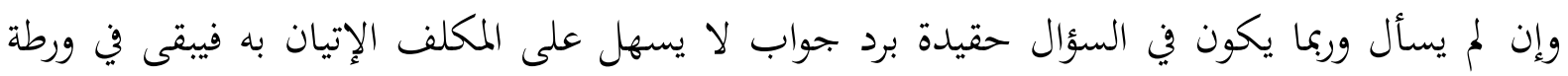

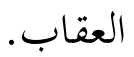

ثالثها- أن يكون المراد رفع الكلام بالتعظيم أي لا تجعلوا لكلامكم ارتفاعاً على كلام النبي في

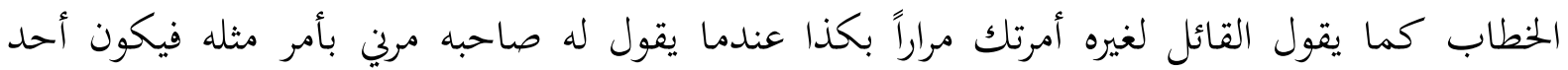


الكلامين أعلى وأرفع من الآخر والأول أصح والكل يدخل في حكم المراد لأن المنع من رفع الصوت لا

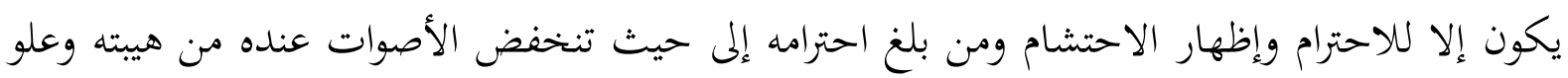

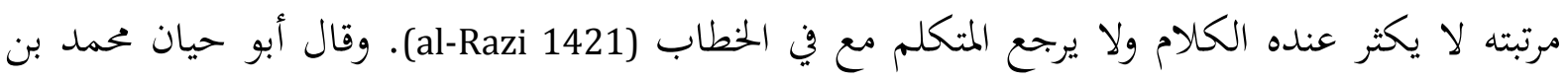

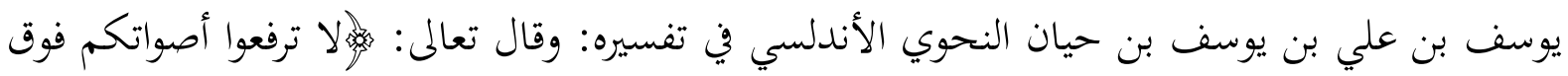

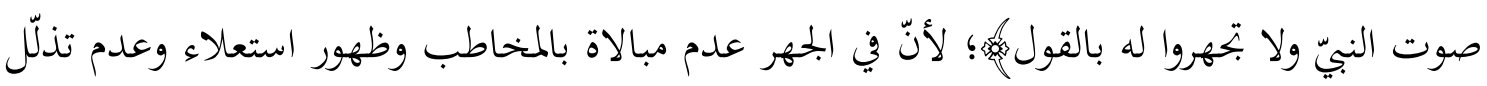
.(Abu Hayyan chpt. 189, 6:36)

\section{الصوت من منظور السنة المطهرة}

قد اهتم رسول الله لعدم رفع الصوت ويرغب على الصوت الخفيض، وإذا نتأمل في سيرته المباركة محاورته

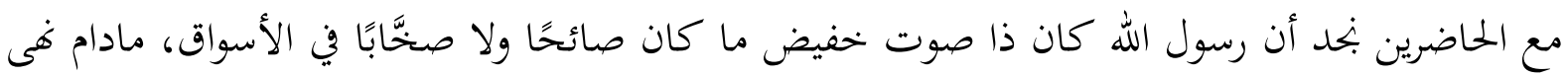
الله عن رفع الصوت وذّّ عن رافعها فالرسول الله أول من اتبع وسلك على هدى القيط القرآن الكريم، نذكر هنا بعض الأحاديث التى ترغب على خفض الصوت عند الكلام، وتنهى عن رفعها عند الحوار مع الأخرين.

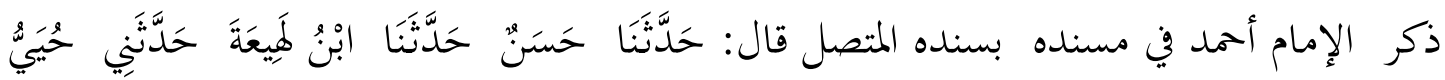

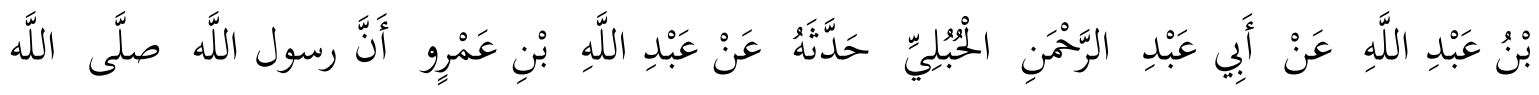

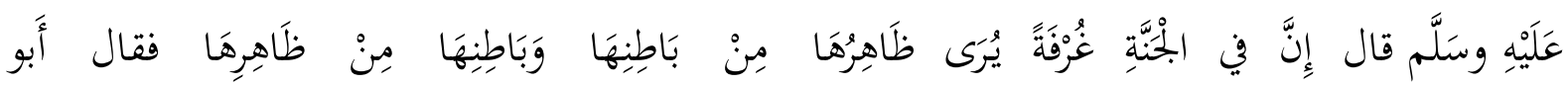

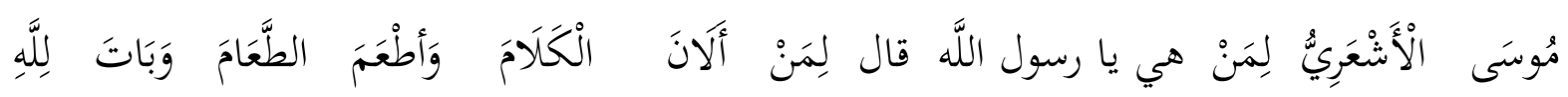

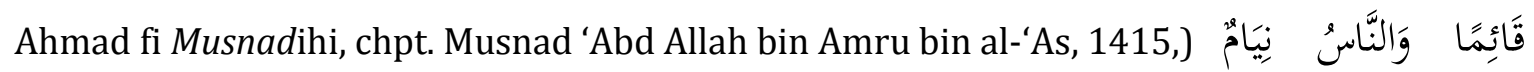

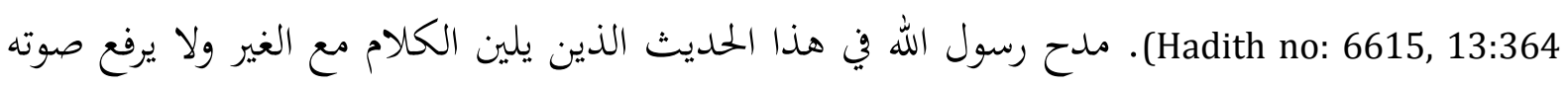

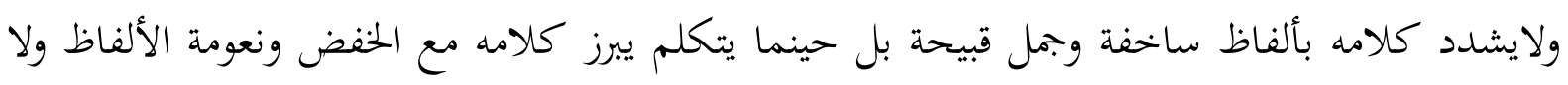
يؤذى شخصًا أخر ولا يجرح قلبه.

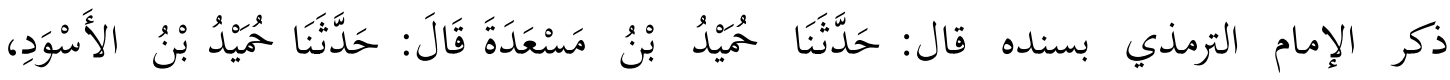

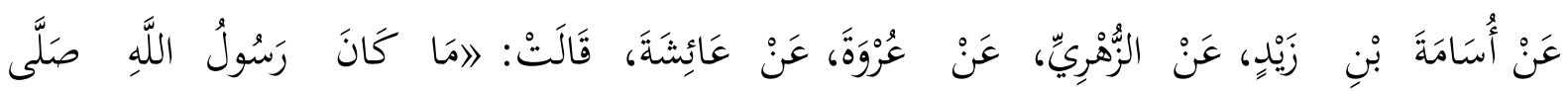

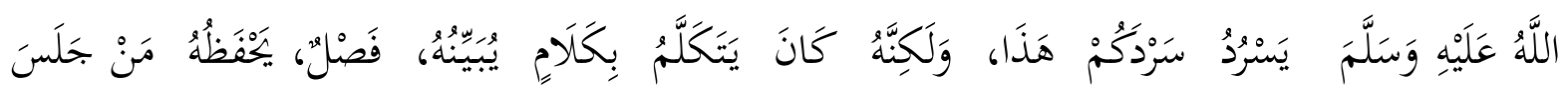

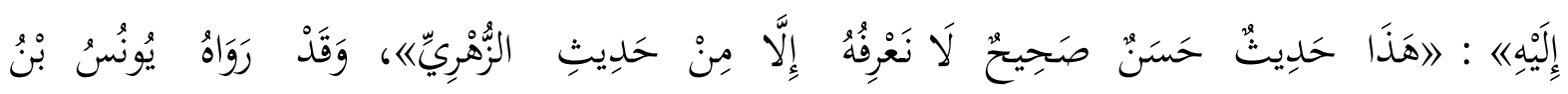

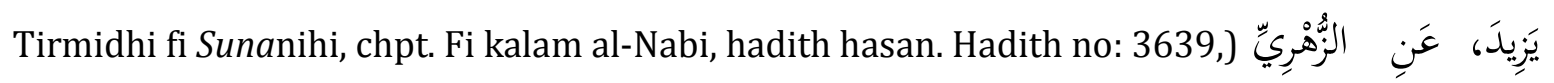


5:600) أشارت سيدة عائشة الصديقة رضى الله عنها في هذا الحديث المبارك عن طرز الكلام وميزته عند

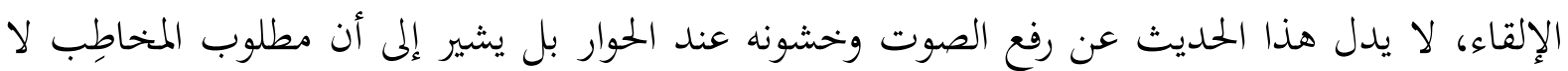

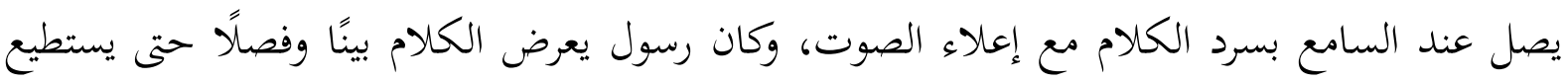
يجفظه منْ جلس حوله في بحلس واحلٍٍ. وقال أبو العلا محمد عبد الرحمن بن عبد الرحيم المباركفورى في

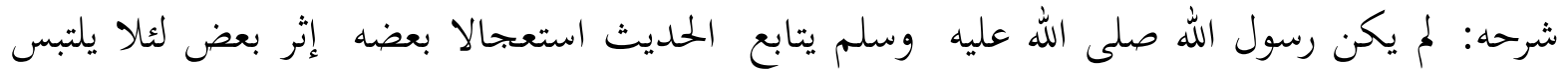

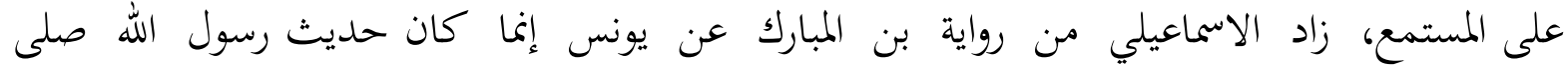

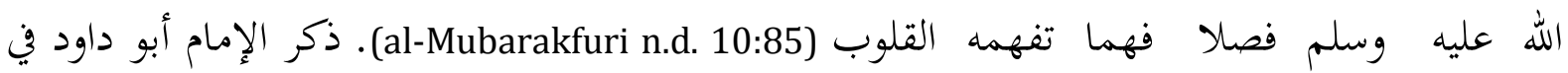
سننه عن وصف كلام سيدنا رسول الله صلى الله عليه وسلم وجاء بالحديث في سننه بسند متصل قال:

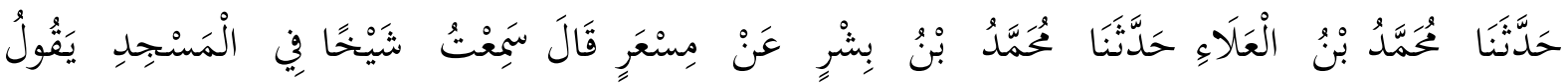

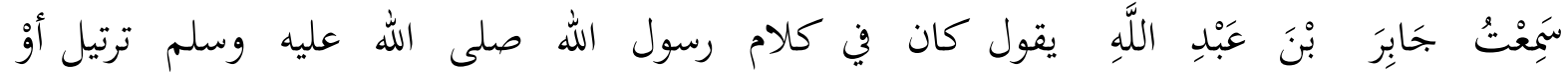
ترسيل (Abu Dawud chpt. al-Hadi fi al-Kalam. No. 4198, 12:466) قال محمد شمس الحق العظيم آبادى عن شرح هذا الحديث: (ترتيل) أي تأن وتمهل مع تبيين الحروف والحركات بحيث يتمكن السامع من عدها (أو ترسيل) شك من من الراوي، ومعنى الترتيل والترسيل واحد، وفي بعض النسخ بالواو فهو عطف تفسير . Muhammad Samsul Haq, 'Awn al-Ma’bud)

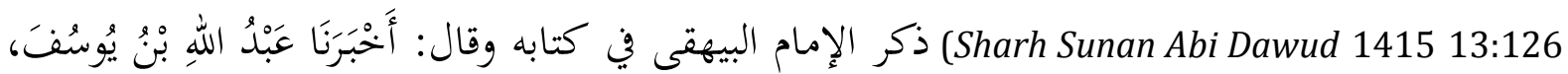

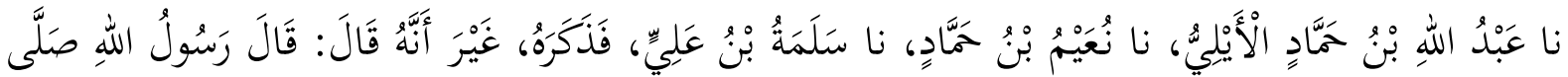

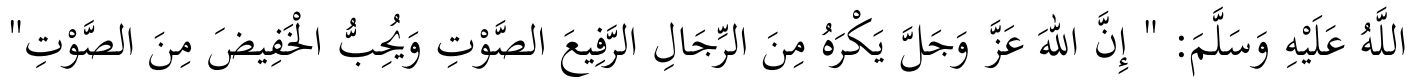

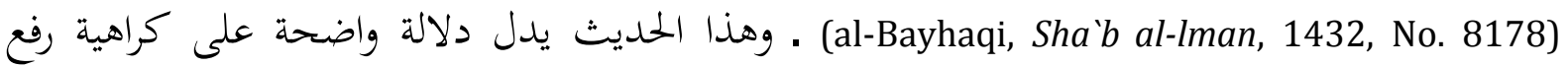
الصوت عند الكلام والمكالمة مع الغير، وهو الموافق مع الأية القرآنية التى ذكرت في سورة لقمان كنصيحة لإبنه الحبيب عن تحربة الحياة الدنيا والمعاملة مع الأخرين في داخل المجتمع وخحارجه، وهى التربية المقبولة عند الله تعالى حتى ذكرت في القرآن الكريم عبرة وعظة لجميع البشر قاطبة بغض النظر عن العهود والعصور جيلا بعد جيلٍ، وكيف لا وله فوائد عظيمة للناس في كل المراحل الاجتماعية والسياسية، وبنية أكوان

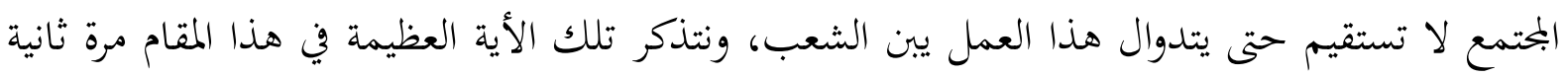

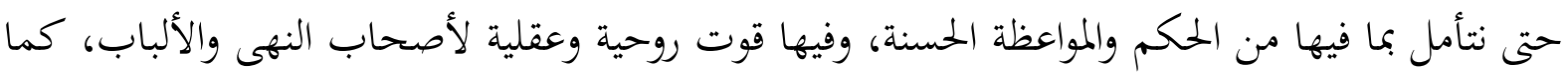

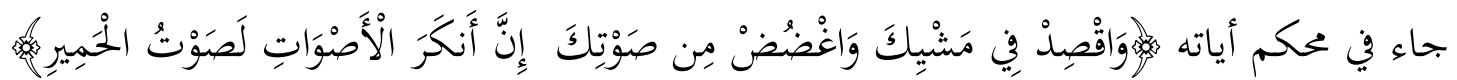


(al-Quran 31:19)، وهناك حديث أخر وهو شاهد لحديث الإمام البيهقى الذى ذكر في شعب الإيمان

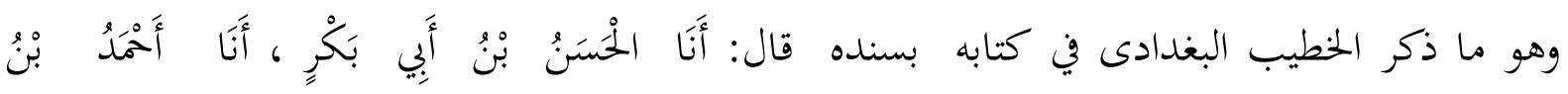

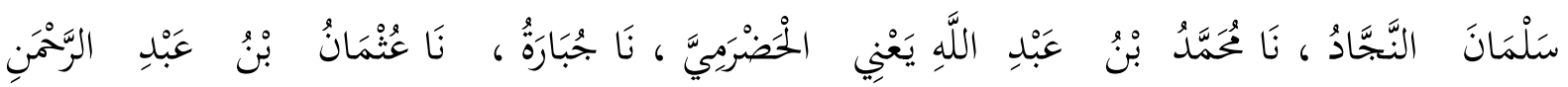

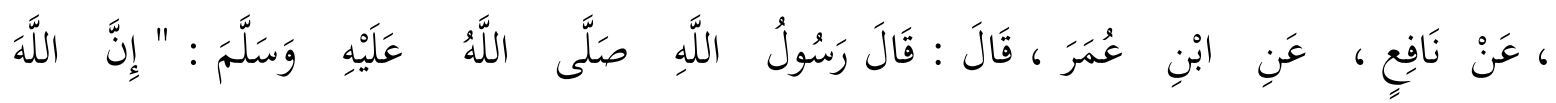

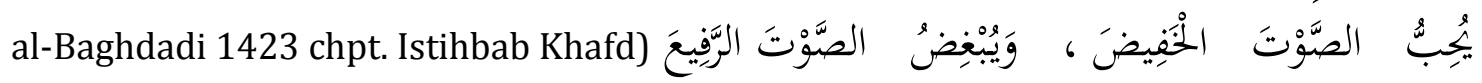

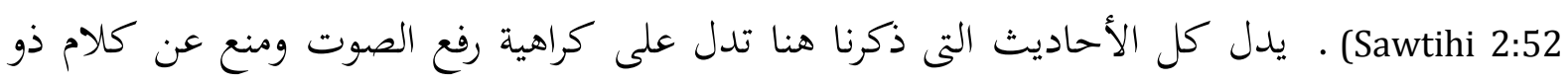

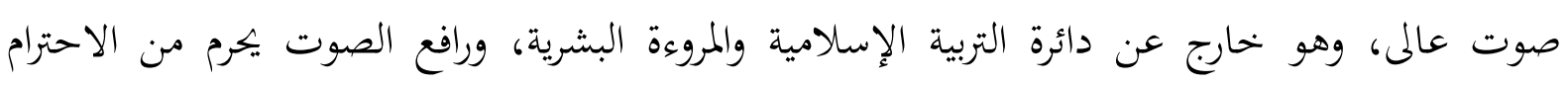
والكرامة عن جيرانه وأصحابه الذين يعيشون حوله ولو كان معه علاقة وثيقة ومحبة دائبة منذ الصغار.

\section{التجربة الشخصية عن الصوت الرفيع}

نذكر في هذه المقالة عن التجربة الشخصية حول الرفع الصوت ونتيجته البائدة بين الناس، حكى لى صديق

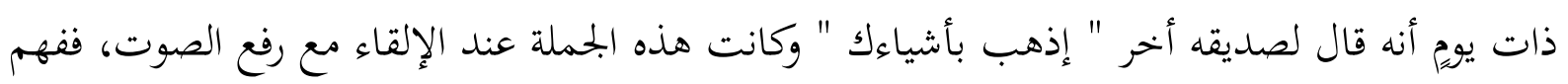

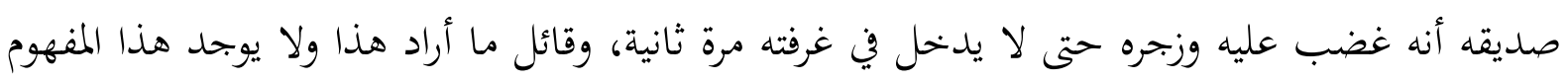

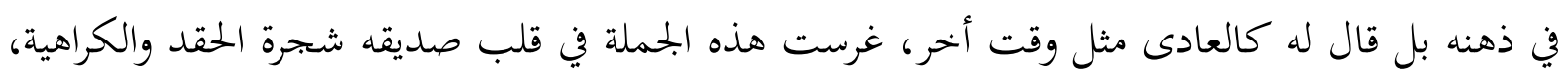

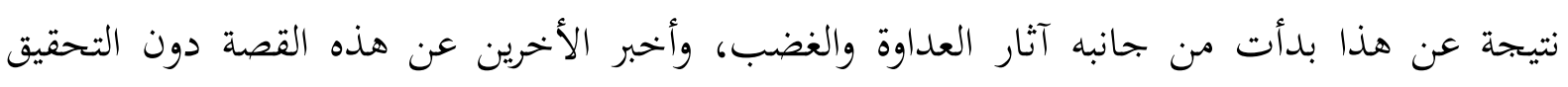

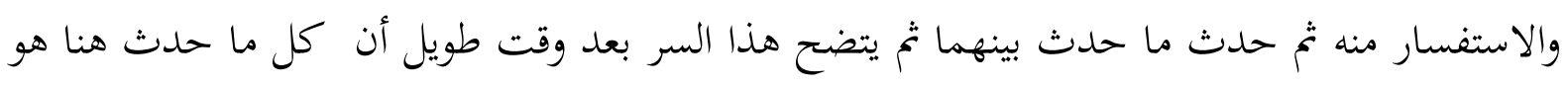

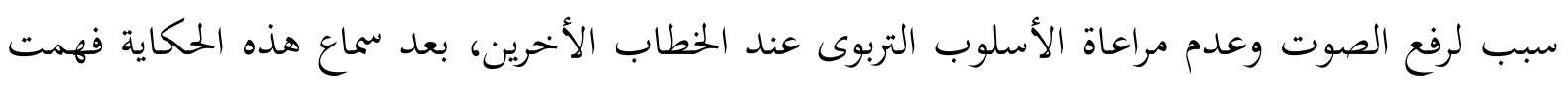

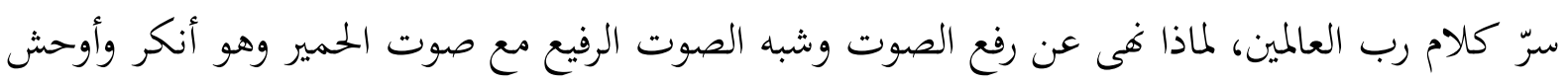

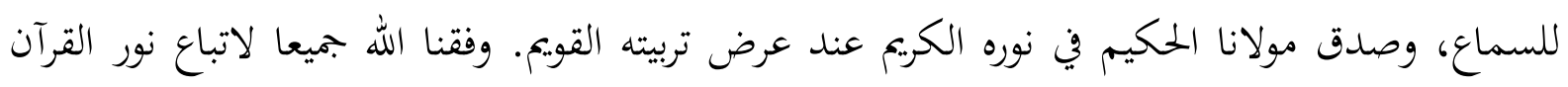
واجعله لنا نورا وحجة يا رب العالمين.

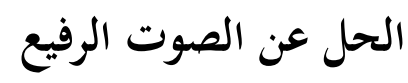

إنَّ الله سبحانه تعالى خلق الناس وأعطى ميزة لكل فرد بشكل مختلف وليس على وتيرة واحدة، إذا نتأمل

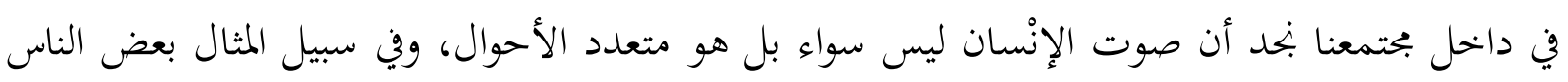

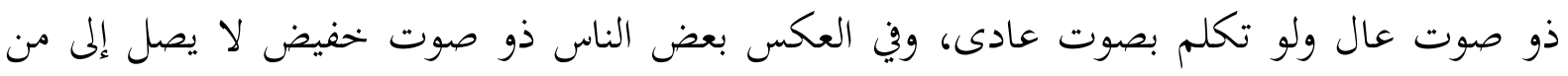


حوله ولو قريب من المسافة، نتذكر صديقنا الحميم محمد غلام الرحمن، درسنا في جامعة الأزهر الشريف في

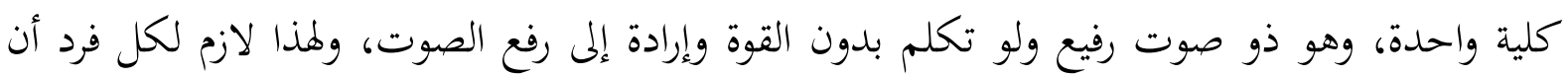

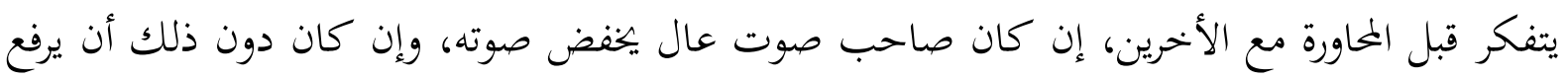

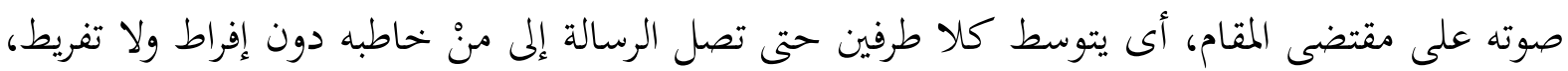

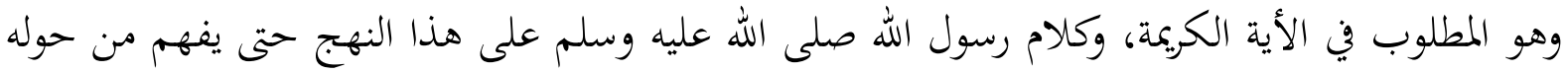

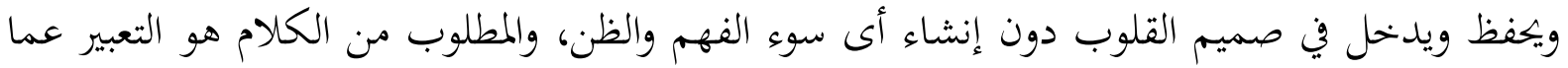

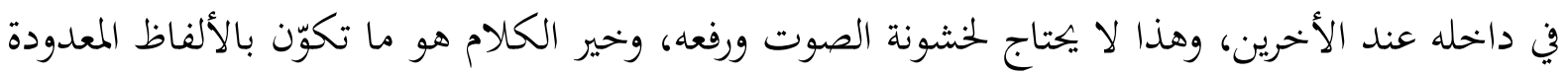

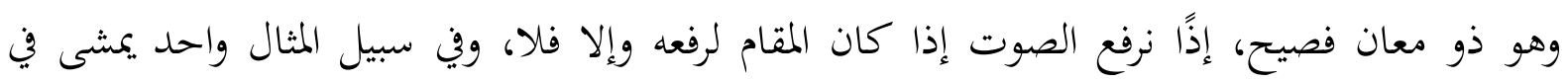

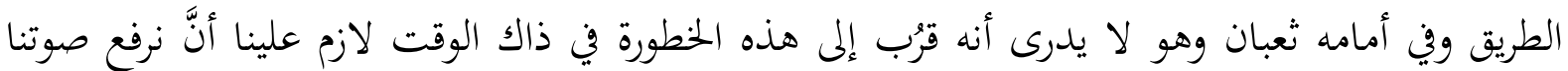

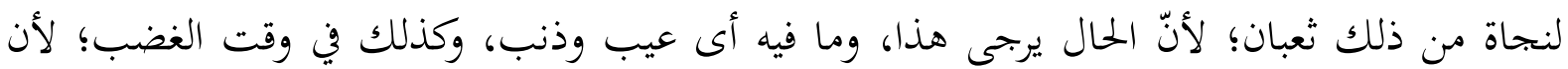

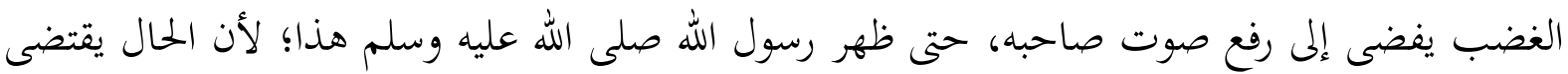

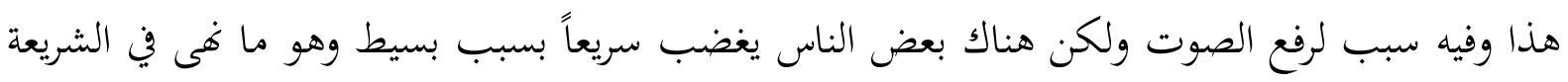

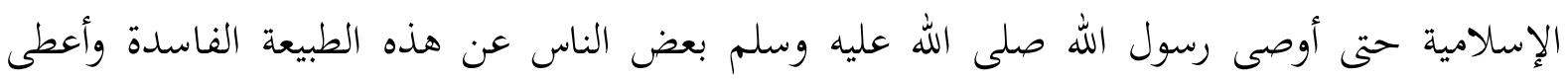
الأدوية من صيدليته المباركة علاجا لهذا.

خلاصة الكلام عن حل رفع الصوت وخطورته وهو حينما نتكلم لازم علينا أن نلاحظ المقام

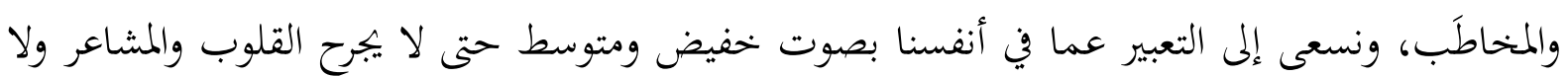

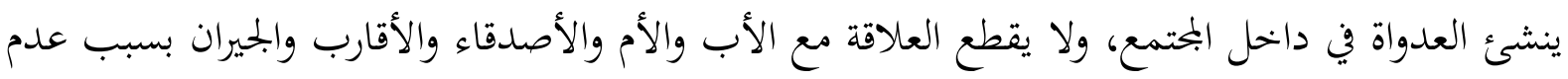

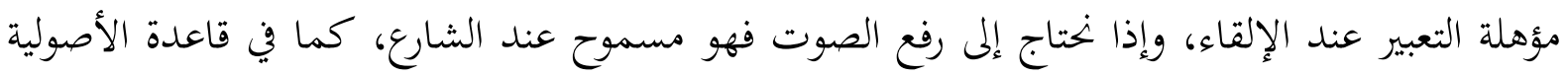

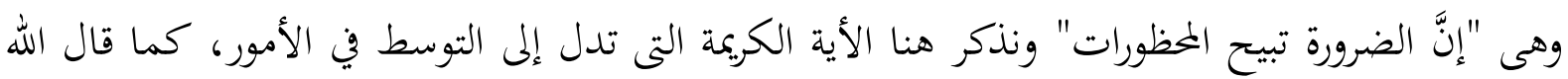

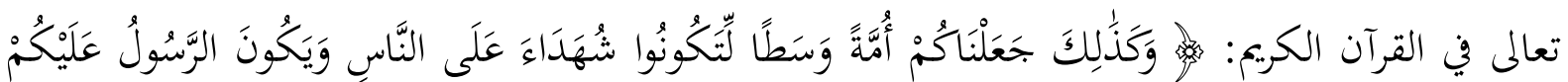

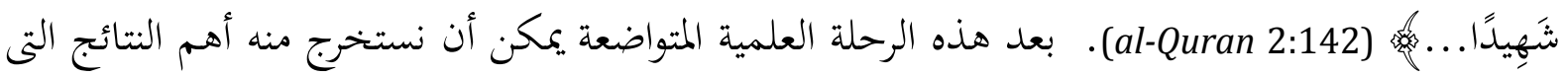

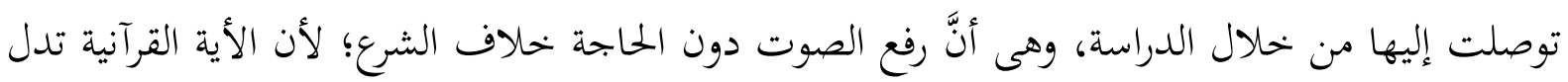

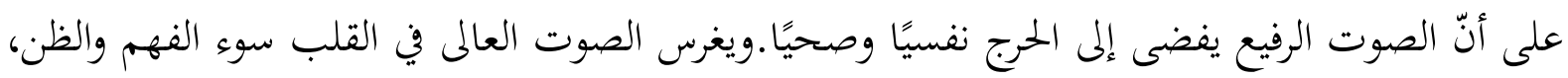

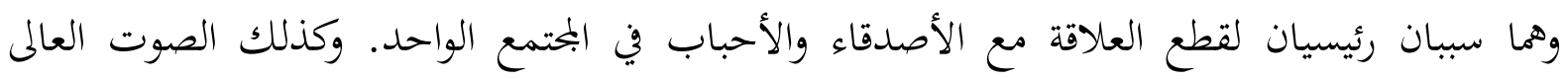
مخالف لعادة المؤمنين والمثقفين، وما كانت أسوة رسول الله صلى الله عليه وسلم أنْ يتكلم بألفاظ 


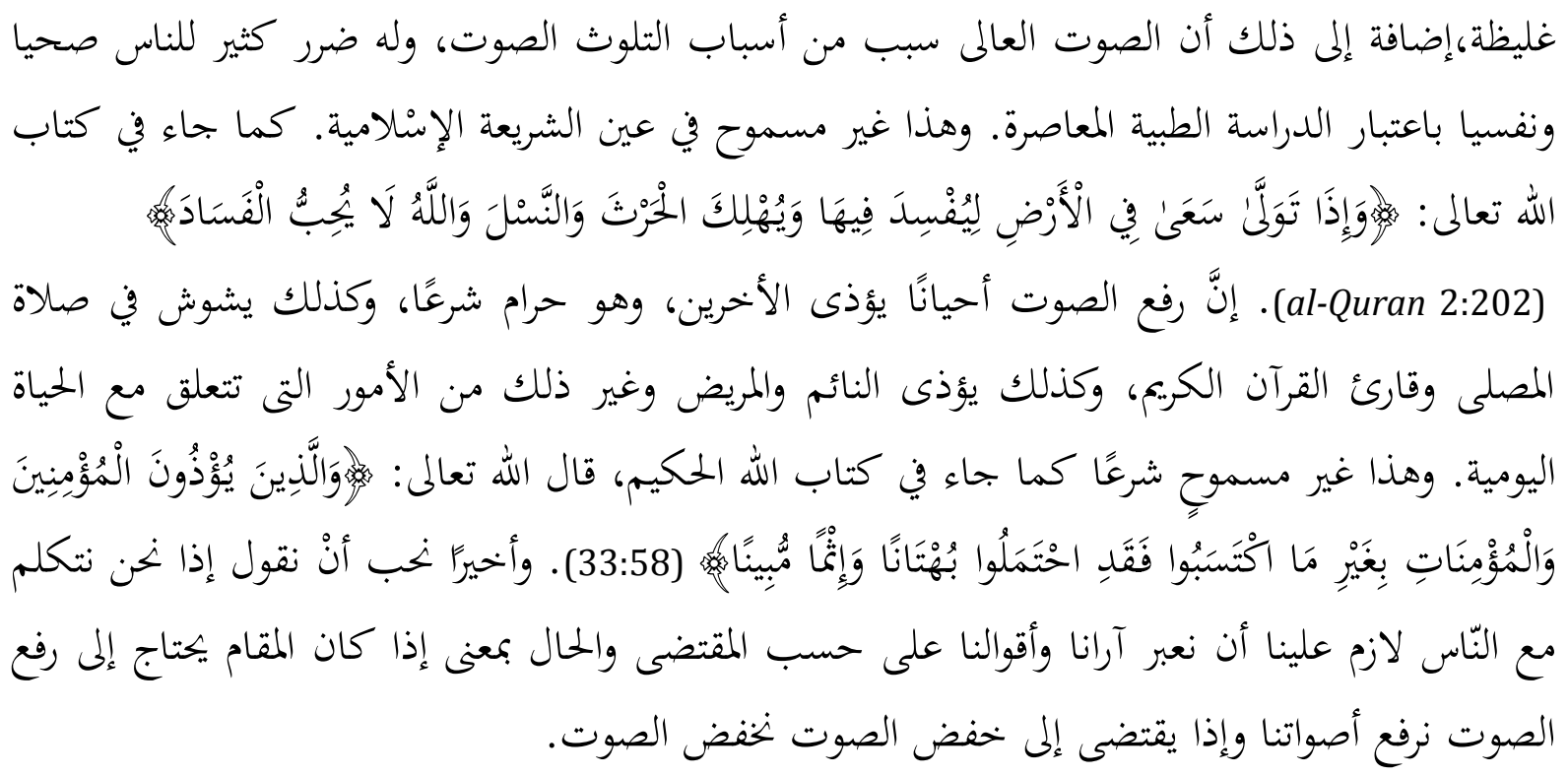

\section{References}

Al-Quran.

Abu-Dawud, Sulayman bin Ishaq. n.d. Sunan Abi Dawud. Tahqiq: Muhammad Muhyi al-Din 'Abd al-Hamid. Beirut: al-Maktabah al-'Asriyyah.

Abu-Tayyib, Muhammad Shams al-Haq al-Ajim Abadi. 1415. 'Awn al-ma'bud sharh Sunan AbiDawud. Beirut: Dar al-Kutub Al-Ilmiyyah.

al-Alusi, Abu al-Fadl Mahmud. n.d. Ruh al-ma'ani fi tafsir al-Qur'an al-'Azim wa Sab'al-Mathani. Beirut: Dar Ihya` al-Turath al-'Arabi.

al-Andalusi. n.d. Abu-Hayyan Muhammad bin Yusuf bin Ali bin Yusuf bin Hayyan. Al-Bahr almuhit. n.p.: n.p.

al-Baghdadi, Ahmad bin 'Ali bin Thabit al-Katib. 1422. Al-Jami li akhlaqi al-rawi wa adab al-sami. (Tahqiq). Rafat Sa'd. Mansoura : Dar al-Wafa.

al-Bayhaqi, Ahmad bin al-Hussain bin 'Ali bin Musa. 1423. Sha'b al-Iman. (Tahqiq). 'Abd al-Ali 'Abd al-Hamd Jamid. Riyadh: Maktabat al-Rushd.

al-Fayumi, Ahmad bin Muhammad bin Ali. 1423. Al-Misbah al-munir. Cairo: Dar al-Hadith.

al-Hasani, Ahmad bin Muhammad bin Mahdi bin Azibah. 1419. Al-Bahr al-madid fi tafsir alQur'an al-Mazid. (Tahqiq). Ahmad Abd Allah al-Qurasi Raslan \& Abbas Jaki. Beirut: Dar al-Kutub al-'Ilmiyyah.

Ibn Manzur, Muhammad bin Mukrim bin Munjir Al-Afriqi Al-Misri. n.d. Lisan al-'Arab. (Tashih). Amin Muhammad 'Abd al-Wahhab \& Muhammad al-Sadiq al-Abidi. Beirut: Dar al-Ihya al-Turath al-'Arabi wa Muassat al-Tariq al-'Arabi.

al-Mubarakfuri, Muhammad `Abd al-Rahman bin Abd al-Rahim. n.d. Tuhfat al-ahwazi bi sharh alJami` al-Tirmidhi. Beirut: Dar al-Kutub al-'Ilmiyyah.

al-Qurtubi, Muhammad bin Ahmad bin Abu Bakar bin Farh. 1384. Al-Jami' li ahkam al-Qur'an. Tahqiq: Ahmad al-Barduni \& Ibrahim al-Fuis. Cairo: Dar al-Kutub al-Misriyah.

al-Razi, Muhammad bin Umar al-Tamimi. 1421. Mafatih al-ghayb. Beirut: Dar al-Kutub al'Ilmiyyah.

al-Saibani, Ahmad bin Muhammad bin Hanbal bin Hilal bin Asad.1416. Musnad al-Imam Ahmad bin Hanbal. (Tahqiq). Ahmad Muhammad Sakir. Cairo: Dar al-Hadith. 


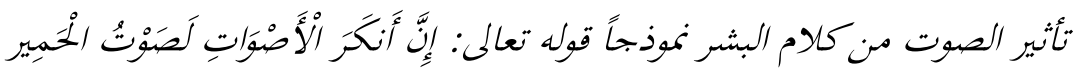

Md Nazmul Hasan \& Md. Mozammel Hoque

al-Tirmidhi, Muhammad bin 'Isah bin Surah bin Musa bin Dahhak. n.d. Al-Jami' al-Sahih Sunan al-Tirmidhi. (Tahqiq). Ahmad Muhammad Sakir et. al. Beirut: Dar Ihya al-Turath alArabi. 